\title{
METODOLOGIAS ATIVAS NO ENSINO SUPERIOR - UM ESTUDO DE CASO DE DESENVOLVIMENTO DE PROJETO
}

\author{
ACTIVE METHODOLOGIES IN HIGHER EDUCATION - A CASE STUDY OF PROJECT \\ DEVELOPMENT \\ Rondinele de Oliveira Moutta ${ }^{1}$; Giseli Capaci Rodrigues ${ }^{2}$ \\ DOI: 10.37702/REE2236-0158.v39p137-146.2020
}

\begin{abstract}
RESUMO
O grande desafio da educação é expandir o ambiente de aprendizagem para além da sala de aula. Alunos de engenharia receberam o desafio de desenvolver um protótipo de um equipamento hidráulico com algum aspecto inovador. A turma se dividiu em grupos para desenvolver seus projetos e, então, estes apresentaram seus protótipos. De acordo com os resultados apresentados pelos alunos, observou-se o que se defende como "princípios e fins da educação nacional": vinculação entre a educação escolar, o trabalho e as práticas sociais. Essa resolução corrobora o que está previsto na Lei de Diretrizes e Bases do Brasil sobre o processo educacional e os quatro pilares da educação. Implementada neste trabalho, a Aprendizagem Baseada em Projetos demonstrou ser eficiente, o que se constatou diante dos relatos dos alunos. A entrega do projeto evidencia que os alunos puderam fazer uma leitura crítica da sociedade, apresentando potencial para compreender a sociedade em que estão inseridos, bem como de influenciar nela a partir das suas atribuições técnicas e profissionais.
\end{abstract}

Palavras-chave: ensino de engenharia; metodologias ativas; aprendizagem baseada em projeto.

\begin{abstract}
The great challenge of education is expanding the learning environment beyond the classroom. Engineering students were challenged to develop a prototype of some innovative looking hydraulic equipment. The class split into groups to develop your projects and then presented their prototypes. According to the results presented by the students, it was observed what is defended as "principles and purposes of national education": linking education, work and social practices. This resolution corroborates what is foreseen in the Brazilian Guidelines and Bases Law on the educational process and the four pillars of education. Implemented in this work, project-based learning proved to be efficient before student reports. The delivery of the project shows that the students were able to make a critical reading of society, presenting potential to understand the society in which they are inserted, as well as to influence it from their technical and professional attributions.
\end{abstract}

Keywords: engineering teaching; active methodologies; project-based learning.

1 Prof. Dr. do UniFOA - Centro Universitário de Volta Redonda, Volta Redonda, RJ; fiscal de contratos e chefe de serviços na divisão de recuperação ambiental no Instituto Estadual do Ambiente - INEA, Rio de Janeiro, RJ; romoutta@yahoo.com.br

2 Prof. Dra. Adjunta da Unigranrio - Universidade do Grande Rio, Duque de Caxias, RJ; giseli.rodrigues@unigranrio.edu.br 


\section{INTRODUÇÃO}

A formação de cidadãos críticos tem como um de seus pilares a formação escolar.

A Lei de Diretrizes e Bases (LDB) da educação brasileira estabelece princípios e finalidades educacionais que vislumbram o educando e a sociedade de forma integrada em todos os seus aspectos: o pleno desenvolvimento do educando, seu preparo para o exercício da cidadania e sua qualificação para o trabalho (BRASIL, 1996). A comunidade de educadores vem defendendo a formação da cidadania como objetivo básico do ensino, ensinar com intuito primordial de desenvolver no aluno a capacidade de participar criticamente nas questões da sociedade.

Para tanto, o educador tem que selecionar os conteúdos de modo a relacioná-los com o cotidiano do aluno. Por exemplo, deve-se levar para a sala de aula discussões de aspectos sociais, a fim de instigar no aluno o senso crítico sobre as tomadas de decisões para solucionar o problema em questão. Portanto, não se deve apenas tratar de maneira isolada determinado aspecto social, sendo necessária uma discussão crítica de suas implicações sociais. $\mathrm{Na}$ escolha dos temas que serão abordados, o professor possui certa autonomia, de acordo com um currículo mínimo que deve ser abordado, para considerar o momento histórico da sociedade, o ambiente em sala de aula, o dia a dia dos alunos, sua realidade social, cultural, a comunidade na qual vivem entre outros fatores e, assim, ensinar para formar o cidadão-aluno.

Visando à construção de um modelo de desenvolvimento comprometido com a cidadania e ajudando o aluno a não pensar somente em si, mas em toda a sociedade na qual está inserido, é preciso que se discuta a necessidade de uma mudança de atitudes e valores das pessoas para o uso mais adequado das tecnologias e para a preservação do ambiente; faz-se necessário, também, mostrar a complexidade dos aspectos sociais, econômicos, políticos e ambientais, que estão envolvidos nos problemas da sociedade. Neste sentido, a aplicação de metodologias ativas tem sido uma alternativa muito promissora nos últimos anos para conduzir o processo ensinoaprendizagem nessa perspectiva.

\section{FUNDAMENTAÇÃO TEÓRICA}

\section{A Lei de Diretrizes e Bases e os quatro pilares da educação}

A Lei de Diretrizes e Bases da educação nacional sancionada em 1996 no Brasil inovou quando ampliou o conceito de educação colocando-o para além dos limites da escola, abraçando os processos que se desenvolvem "na vida familiar, na convivência humana, no trabalho, nas instituições de ensino e pesquisa, nos movimentos sociais e organizações da sociedade civil e nas manifestações culturais" (BRASIL, 1996, n.p.).

Trata-se de formar o cidadão-aluno para sobreviver e atuar de forma responsável e comprometida nesta sociedade científicotecnológica, na qual as ciências aparecem como relevante instrumento para investigação, produção de bens e desenvolvimento socioeconômico e interfere diretamente no cotidiano das pessoas (MARTINS; MARIA; AGUIAR, 2003).

Nesse contexto, o Brasil, à época, estava estreitamente alinhado com a discussão sobre o processo ensino-aprendizagem internacional, visto que estabeleceu suas diretrizes e bases (LDB, Lei $\mathrm{N}^{\circ}$ 9.394/96) três anos antes do relatório publicado pela Organização das Nações Unidas para a Educação, a Ciência e a Cultura (UNESCO), no qual se discute que o aprendizado deve seguir por toda a vida como principal consequência da sociedade do conhecimento, e deve se orientar por quatro etapas fundamentais, conhecidas como os quatro pilares da educação (DELORS, 2012). Esses pilares elencam quatro aprendizagens fundamentais para $\mathrm{o}$ desenvolvimento cognitivo e social que devem nortear a educação no século XXI, sendo eles: aprender a conhecer (adquirir instrumentos de compreensão); aprender a fazer (para poder agir sobre o meio envolvente); aprender a viver juntos (cooperação com os outros em todas as atividades humanas); e finalmente aprender a ser (conceito principal que integra todos os 
anteriores). Essas quatro vias do saber se caracterizam por contemplar questões cognitivas, assim como questões do relacionamento humano, e constituem apenas uma, uma vez que existem pontos de interligação entre elas (DELORS, 2012).

Nesse sentido, percebe-se que a aplicação de tais diretrizes é um caminho sem volta para uma sociedade tecnológica dos tempos modernos.

\section{Educação no ensino superior}

No ensino superior os alunos vivenciam uma particularidade: a ocorrência de os docentes do ensino superior, em geral, não possuírem uma formação pedagógica, mas sim uma formação tecnicista e específica de determinada área profissional, o que torna o processo ensino-aprendizagem um desafio para a implantação do projeto pedagógico curricular.

$\mathrm{Na}$ maioria das instituições de ensino superior, embora seus professores possam ser detentores de experiência significativa, predomina o despreparo e até desconhecimento do que seja um processo ensino-aprendizagem, pelo qual passam a ser responsáveis a partir do instante em que ingressam no ambiente de aprendizagem.

O aumento dos saberes, que permitem compreender melhor o ambiente sob os seus diversos aspectos, favorece o despertar da curiosidade intelectual, estimula o sentido crítico e permite compreender o real, mediante a aquisição de autonomia e capacidade de discernir (DELORS, 2012). Assim, o professor da atualidade precisa estar cada vez mais colocado como mediador no processo de aprendizagem em vez de transmissor do conhecimento. Segundo Masetto (1998), o papel do docente é ser elemento orientador, incentivador.

\section{Metodologias ativas}

Algumas Instituições de Ensino Superior (IES) buscam minimizar lacunas no processo de ensino e aprendizagem adotando novas metodologias e organizações curriculares, na perspectiva de integrar teoria/prática, ensino/serviço, com destaque para as metodologias ativas de aprendizagem (MARIN et al., 2010).

O principal objetivo desse modelo de ensino é incentivar os alunos para que eles aprendam de forma autônoma e participativa, a partir de problemas e situações reais. A proposta é que o estudante esteja no centro do processo de aprendizagem, participando ativamente e sendo responsável pela construção do conhecimento.

São muitos os benefícios de trazer as metodologias ativas para dentro da sala de aula. Entre eles destaca-se, principalmente, a transformação na forma de conceber o aprendizado - ao proporcionar que o aluno pense de maneira diferente e que ele possa resolver problemas conectando ideias que, em princípio, pareceriam desconectadas.

Entre as metodologias ativas mais comuns está a Aprendizagem Baseada em Projetos ou em Problemas. A Aprendizagem Baseada em Problema tem como propósito fazer com que os estudantes aprendam através da resolução colaborativa de desafios. Ao explorar soluções dentro de um contexto específico de aprendizado, que pode utilizar a tecnologia e/ou outros recursos, essa metodologia incentiva a habilidade de investigar, refletir e criar diante de uma situação (SAKAI; LIMA, 1996).

A discussão de um problema se desenvolve em duas etapas: na primeira o problema é apresentado e os estudantes formulam objetivos de aprendizado a partir de discussões. $\mathrm{Na}$ segunda etapa, após estudo individual realizado fora do grupo, os estudantes rediscutem o problema à luz dos novos conhecimentos adquiridos.

A Aprendizagem Baseada em Projetos também é fundamentada na Aprendizagem Baseada em Problemas, porém exige que os alunos coloquem "a mão na massa", uma vez que se propõe que eles investiguem como chegar à resolução. Um bom exemplo disso é o movimento maker, "faça você mesmo", que propõe o resgate da aprendizagem "mão na massa" e que traz o conceito de "aprendendo a fazer" (MORÁN, 2015).

A Aprendizagem Entre Times, team based learning (TBL), tem por finalidade a formação de equipes dentro da turma, através do 
aprendizado que privilegia o fazer em conjunto para o compartilhamento de ideias. $\mathrm{O}$ professor pode trabalhar esse tipo de aprendizagem através de um estudo de caso ou projeto, para que os alunos resolvam os desafios de forma colaborativa. Dessa forma, eles aprendem uns com os outros, empenhando-se para formar o pensamento crítico, que é construído por meio de discussões e reflexões entre os grupos.

$\mathrm{Na}$ metodologia de Aula Invertida, as instruções dos conteúdos se realizam fora da sala de aula, por meio de videoaulas, leituras e outras mídias, sendo o tempo de sala de aula liberado para realização de atividades ativas, nas quais os estudantes praticam e desenvolvem o que aprenderam com o auxílio e supervisão do professor (DATIG; RUSWICK, 2013).

Para Morán (2015), a tecnologia proporciona hoje integração entre todos os espaços e tempos. O processo de ensinar e aprender acontece numa interligação simbiótica, profunda e constante entre o que chamamos mundo físico e mundo digital. Não são dois mundos ou espaços, mas um espaço estendido, uma sala de aula ampliada, que se mescla e se hibridiza constantemente.

Ainda segundo Morán (2015), as metodologias precisam acompanhar os objetivos pretendidos. Isso é, se queremos que os alunos sejam proativos, precisamos adotar metodologias em que os alunos se envolvam em atividades cada vez mais complexas, em que tenham que tomar decisões e avaliar os resultados, com apoio de materiais relevantes; se queremos que sejam criativos, eles precisam experimentar inúmeras possibilidades de mostrar sua iniciativa criativa.

\section{OBJETIVOS}

1) Potencializar o aprendizado do aluno por meio de: interatividade, trabalho em equipe, conhecimento do mercado profissional a ser inserido, habilidades de pesquisa, capacidade criativa e de organização.

2) Desenvolver um protótipo de um equipamento hidráulico com algum aspecto inovador.

\section{ASPECTOS METODOLÓGICOS}

Aplicou-se o método da Aprendizagem Baseada em Projetos com uma turma da disciplina de Física 2 do $3^{\circ}$ período do curso de Engenharia Civil do Centro Universitário de Volta Redonda - UniFOA, no ano de 2017. A turma possuía 20 alunos, os quais voluntariamente preencheram um questionário para avaliação do projeto desenvolvido, como segue abaixo:

Figura 1 - Questionário para avaliação do projeto desenvolvido

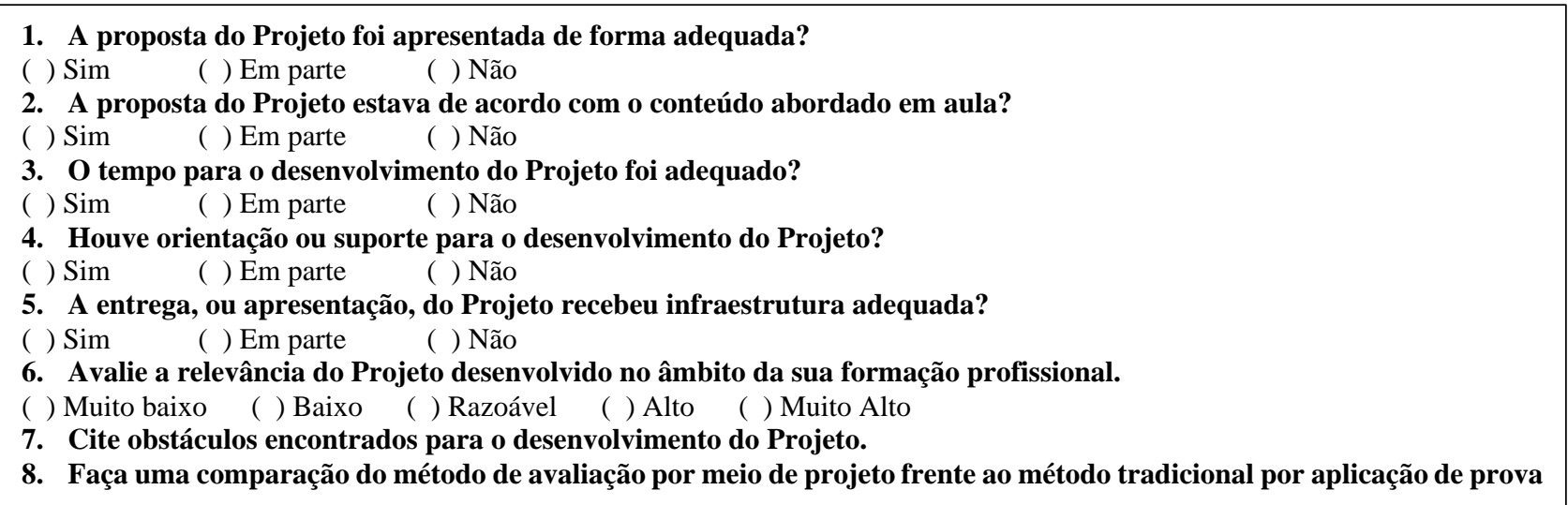

Fonte: elaborada pelos autores.

Os alunos tiveram que se apresentar enquanto uma empresa (propondo razão social e logomarca). A tarefa foi apresentar uma tecnologia de um equipamento que operasse por meio do uso de pistões hidráulicos, ou seja, por escoamento de fluidos, em uma situação hipotética em que eles teriam de vender com a 
finalidade de atender a um determinado setor.

Para isso:

a) buscaram em qual mercado atuar e suas principais características;

b) abordaram a utilidade e o diferencial do equipamento proposto;

c) foi proposto aos alunos que apresentassem um folder e/ou ficha técnica com características do protótipo versus características simuladas em escala real (tais como dimensões, alcance, capacidade de carga ou esforço; algumas características do protótipo se estenderiam ao equipamento em tamanho real (conforme Figura 2). Nesse sentido exigiu-se que apresentassem em anexo, fora da ficha técnica, os cálculos de esforço, capacidade, etc. que fossem possíveis e apropriados ao protótipo proposto. Estes cálculos demonstrativos deveriam abordar principalmente $\mathrm{o}$ conteúdo teórico visto nas aulas sobre escoamento de fluidos.

\section{CX220 - CAMPO DE TRABALHO}

\begin{tabular}{|c|c|c|c|c|}
\hline LANÇA & $\mathrm{mm}$ & \multicolumn{3}{|c|}{5.650} \\
\hline $\begin{array}{c}\text { BRAÇO DE } \\
\text { ESCAV̌AÇAO }\end{array}$ & $\mathrm{mm}$ & 2.400 & 2.940 & 3.500 \\
\hline $\mathrm{A}$ & $\mathrm{mm}$ & 9.445 & 9.926 & 10.320 \\
\hline $\mathrm{A}^{\prime}$ & $\mathrm{mm}$ & 9.270 & 9.765 & 10.165 \\
\hline $\mathrm{B}$ & $\mathrm{mm}$ & 6.141 & 6.681 & 7.241 \\
\hline $\mathrm{B}^{\prime}$ & $\mathrm{mm}$ & 5.938 & 6.505 & 7.062 \\
\hline $\mathrm{C}$ & $\mathrm{mm}$ & 9.450 & 9.670 & 9.579 \\
\hline $\mathrm{D}$ & $\mathrm{mm}$ & 6.661 & 6.908 & 6.935 \\
\hline $\mathrm{E}$ & $\mathrm{mm}$ & 3.555 & 3.625 & 3.553 \\
\hline $\mathrm{F}$ & $\mathrm{mm}$ & 3.830 & 3.432 & 2.857 \\
\hline $\mathrm{G}$ & $\mathrm{mm}$ & 5.283 & 5.812 & 6.608 \\
\hline
\end{tabular}

\begin{tabular}{|l|c|c|c|c|}
\hline \multicolumn{5}{|l|}{ FORÇA DE DESAGREAÇÃO } \\
\hline Caçamba & daN & 13.234 & 13.234 & 13.234 \\
\hline Braço de escavação & daN & 11.798 & 9.932 & 9.059 \\
\hline
\end{tabular}

\begin{tabular}{|l|c|c|c|c|}
\hline \multicolumn{5}{|l|}{ COM O POWER BOOST LIGADO } \\
\hline Caçamba & $\mathrm{daN}$ & 14.368 & 14.368 & 14.368 \\
\hline Braço de escavaçăo & $\mathrm{daN}$ & 12.810 & 10.784 & 9.836 \\
\hline
\end{tabular}

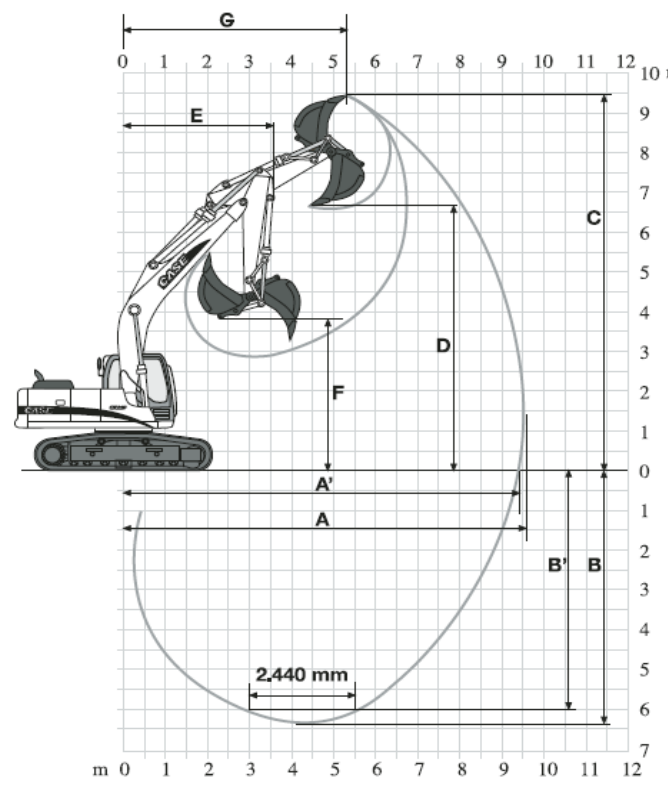

Fonte: Case Construction.

\section{RESULTADOS E DISCUSSÃO}

Este trabalho foi elaborado tomando-se como referência a Lei de Diretrizes e Bases da Educação Nacional (LDB Lei no 9.394/1996) e os quatro pilares da educação (DELORS, 2012), a partir dos quais se propôs a exploração e o desenvolvimento de diversas habilidades nos alunos. Visto que este trabalho foi elaborado em 2017, dois anos antes da publicação das Diretrizes Curriculares Nacionais do Curso de Graduação em Engenharia (DCN Resolução $n^{\circ}$ 2/2019), destaca-se aqui o zelo pela qualidade no ensino de engenharia, com uma postura que visa à atualização e o cumprimento das diretrizes para o ensino.

Ao receberem a proposta de trabalho, os alunos se dividiram em cinco grupos distintos. Com a liberdade que receberam, cada grupo apresentou uma proposta distinta de projeto, conforme abaixo:

Projeto 1: andaime tipo sanfona para bombeamento automatizado de concreto;

Projeto 2: braço mecânico;

Projeto 3: guindaste;

Projeto 4: broca ortodôntica;

Projeto 5: grua pórtica.

Os alunos tiveram oportunidade de desenvolver habilidades como organização, 
formação de equipe, trabalho em equipe, criatividade, comunicação técnica e comercial. Eles foram capazes de criar uma empresa fictícia, com razão social e logomarca; ainda, de criar um produto (em alguns casos puderam apresentar inovações), criar um folder dessa empresa e fazer a publicidade de seu portfólio.

De posse do questionário respondido pelos alunos, algumas análises puderam ser feitas, destacando o desempenho deles frente à proposta que receberam.

Gráfico 1 - Gráfico representativo de parte da pesquisa, em forma de questionário, realizada com alunos que elaboraram uma proposta de projeto de equipamento hidráulico

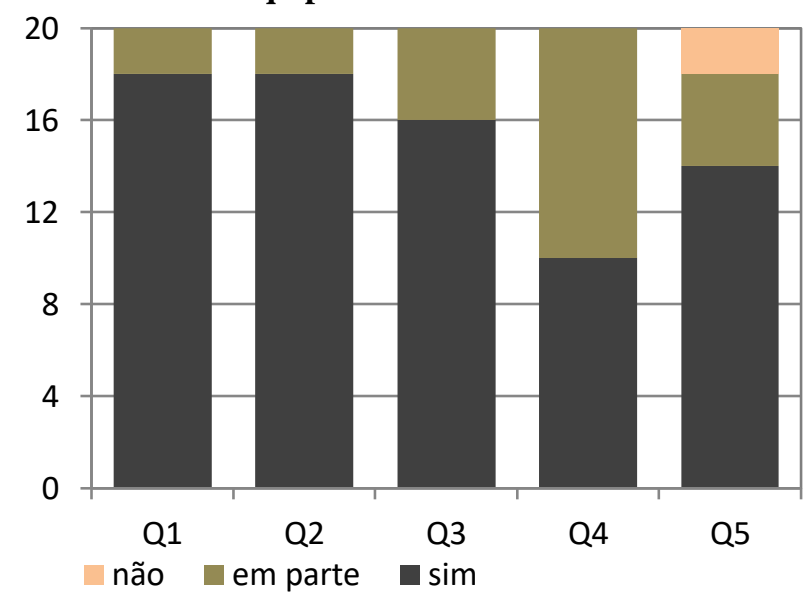

Fonte: elaborado pelos autores.

Sobre Q1 e Q2: os alunos declararam ter entendido claramente a proposta do trabalho e que ela estava de acordo com o conteúdo didático apresentado em sala aula, exceto por quatro alunos. Visto que $90 \%$ dos alunos responderam sim, há indícios de que a exposição prévia do conteúdo didático em aula tornou $\mathrm{o}$ assunto familiar e isso facilitou $\mathrm{o}$ entendimento por parte dos estudantes. Neste contexto, os alunos foram capazes de enxergar a aplicação prática do tema abordado em situações reais e em função disso foram capazes de elaborar uma proposta de projeto.

Acerca de Q3: os alunos consideraram o tempo para o desenvolvimento do projeto adequado. Apenas quatro alunos precisariam de mais tempo. Isso evidencia que a familiarização com o conteúdo didático pode ter sido um facilitador, pois foi necessário conhecer os fundamentos teóricos para elaborar uma proposta de projeto, principalmente aquelas inovadoras.

Sobre Q4: a metade dos alunos considerou que não houve suporte adequado para a confecção do protótipo. Para um melhor desempenho seria necessária a utilização de um ambiente adequado que permitisse a confecção e testes dos protótipos, como laboratórios e oficinas. Embora o UniFOA possua ambientes assim, e estes já estivessem previamente disponíveis para utilização, os alunos optaram por outros caminhos para este fim. Dessa forma, alguns encontraram dificuldades em termos de ambiente estruturado para a montagem do protótipo e de logística para leválo ao local de exposição.

Provavelmente esse comportamento ocorreu porque muitos ainda não conseguem transcender um formato conteudista - que ainda se arrasta em todos os níveis educacionais no Brasil -, além de que muitos nem mesmo adquiriram a prática de explorar os conteúdos para além do que é visto em sala de aula. Assim, é comum que alunos se detenham apenas às aulas práticas e projetos montados que já constam em programação prévia apresentada pelos professores.

Acerca de Q5: diante do fato de que todos os alunos receberam a mesma infraestrutura para a apresentação do trabalho, pode-se apreender que $70 \%$ dos alunos foram capazes de entender esta como suficiente. Por outro lado, a falta de familiaridade com o tema ou com o formato de trabalho apresentados pode ter dificultado a exploração desses recursos em tempo limitado por parte de outros.

A questão Q5 teve o intuito de avaliar parâmetros que correspondem ao comportamento profissional. Um dos objetivos do trabalho proposto aos alunos foi estimular o desenvolvimento de habilidades de comunicação técnica e profissional e, com isso, treiná-los para que eles sejam capazes de se adaptar às circunstâncias. Os alunos foram estimulados a compreender a sociedade no sentido de perceber a existência de uma demanda de mercado, ou seja, de uma oportunidade de negócio; tiveram que demonstrar capacidade de entender a demanda; demonstrar conhecimento técnico enquanto 
profissionais para a elaboração de uma proposta de projeto/produto; e demonstrar capacidade de fazer uma comunicação técnica da proposta, elaborada de forma clara e objetiva para um público específico. Oportunidades de negócio (ou problemas técnicos, que são recorrentes num ambiente de trabalho) podem ocorrer nas mais variadas circunstâncias e o profissional deve desenvolver habilidades para ser capaz de superá-las.

Sobre Q6: $50 \%$ dos alunos avaliaram a relevância do desenvolvimento do projeto como alta ou muito alta para a sua formação profissional. Isso evidencia que eles foram capazes de assimilar o conteúdo didático trabalhado previamente em sala de aula e associá-lo às suas atribuições profissionais, bem como enxergar a aplicabilidade desse conteúdo. Com relação aos outros $50 \%$ dos alunos avaliados, a escolha de um projeto que não apresentasse maiores complexidades, como inovação e exploração do conteúdo didático, pode ter levado a um entendimento de que o projeto não apresentou relevância significativa para sua formação profissional.

Acerca de Q7: entre os obstáculos encontrados para o desenvolvimento do projeto, alguns alunos encontraram dificuldades, como relatado também nos questionamentos Q3 a Q5. Reforçando as respostas anteriores, alguns alunos apontaram como obstáculos: o deslocamento para os membros do grupo se reunirem; o deslocamento para levar o protótipo do local onde foi montado até a faculdade; o entrosamento ou afinidade entre os membros dos grupos; o embasamento teórico também foi citado, pois em que pese a individualidade na aprendizagem de cada aluno, há diferenças por exemplo na forma e na intensidade da assimilação do conteúdo didático; a inovação propriamente dita, o que de fato é complexo e pode não ocorrer mesmo com especialistas em determinado tema; visto que não houve a disponibilização de recursos humanos específicos para a elaboração dos protótipos, habilidades manuais também se apresentaram como um obstáculo, pois os próprios alunos precisaram colocar "a mão na massa" para produzir seus protótipos; e, por fim, o tempo para executar todo o projeto, desde a sua concepção até a entrega do protótipo em si, principalmente, pois esse fator pesa sobre todos os demais mencionados anteriormente.

Dois alunos responderam que não encontraram obstáculos para o cumprimento das tarefas. Isto demonstra que as diferenças na individualidade do processo de aprendizagem são latentes e que esses alunos, em particular, teriam preferência por este método de ensino por apresentarem maior afinidade com ele.

Finalmente, sobre Q8: foi solicitada uma comparação do método de avaliação por meio de projeto frente ao método tradicional por aplicação de provas escritas. Entre os alunos questionados, $40 \%$ dos alunos preferiram não dissertar a respeito, o que pode ter ocorrido por se tratar de questões dissertativas. Nessa situação muitos preferem não se dar ao trabalho de responder. Não obstante, entre aqueles que responderam, verificou-se que as respostas foram positivas, havendo menção a diversos aspectos que inclusive foram confirmados com repetições, tais como enriquecimento no aprendizado, melhora na preparação para as circunstâncias práticas reais, maior dinamismo com um aprendizado mais interessante e realista. 
Figura 3 - Exposição dos protótipos apresentados pelos grupos de trabalho. Projeto 1: andaime tipo sanfona para bombeamento automatizado de concreto; Projeto 2: braço mecânico; Projeto 3: guindaste; Projeto 4: broca ortodôntica; Projeto 5: grua pórtica.
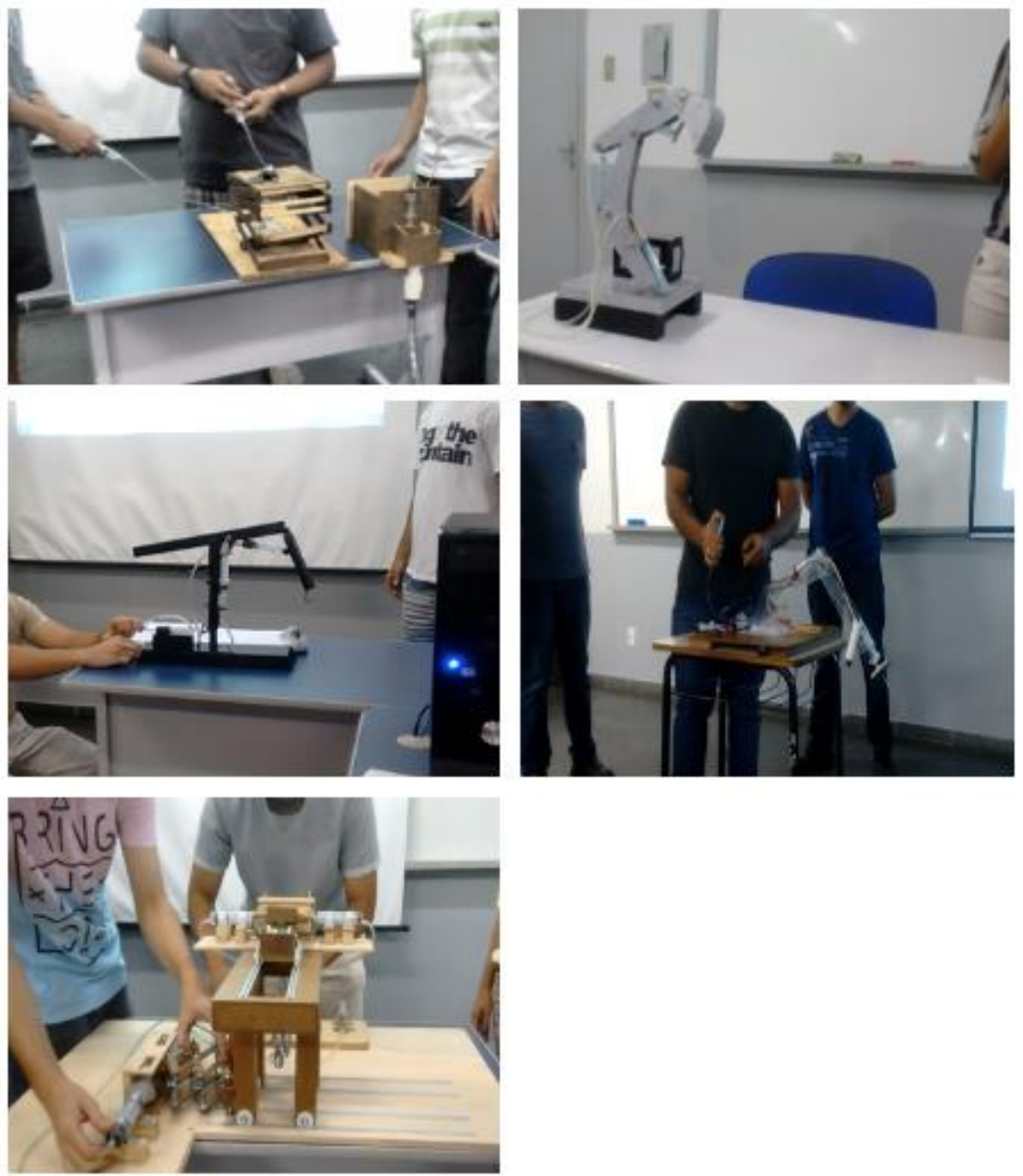

Fonte: acervo dos autores.

Com relação aos projetos desenvolvidos, merecem destaque dois deles, por criatividade e inovação. A broca ortodôntica apresentou uma proposta inovadora quanto à automatização de procedimentos cirúrgicos dentários, em que todo o procedimento poderia ser conduzido por meio do uso de um software específico e comandos manuais. Nessa proposta, segundo os propositores, é possível alcançar maior precisão e maior segurança com relação à possibilidade de contaminação microbiana no procedimento. Outro projeto que merece destaque foi a grua pórtica. Nesse protótipo os alunos propuseram um sistema hidráulico simplificado para operação automatizada de movimentação de cargas nas três dimensões (Figura 3).

\section{CONSIDERAÇÕES FINAIS}

Seguindo-se o que está instituído nas Diretrizes Curriculares Nacionais para o ensino nos cursos de engenharia, elaborou-se esta atividade pedagógica e foi possível observar, de acordo com os resultados apresentados pelos alunos, o que se defende como "princípios e fins da educação nacional" no artigo $3,^{\circ}$ parágrafo XI: vinculação entre a educação escolar, o trabalho e as práticas sociais (BRASIL, 2019). Essa resolução corrobora o que está previsto na Lei de Diretrizes e Bases do Brasil sobre o processo educacional (BRASIL, 1996) e os quatro pilares da educação (DELORS, 2012). 
A educação ao longo de toda a vida se refere à mudança da noção de qualificação, pautada em uma formação única para a noção de competência, que se relaciona a uma formação dinâmica, flexível, condizente com a ênfase atual no trabalho em equipe, na capacidade de iniciativa, na valorização de talentos e aptidões. Essa mudança advém da "desmaterialização" do trabalho que exige, além da técnica, certa competência para as relações interpessoais (DELORS, 2012).

A implementação de metodologias ativas está instituída nas Diretrizes Curriculares Nacionais para o ensino nos cursos de engenharia no Brasil (BRASIL, 2019). Neste trabalho a implementação se deu por intermédio da metodologia Aprendizagem Baseada em Projetos, método o qual demonstrou ser eficiente diante dos relatos dos alunos. A entrega do projeto evidencia que os alunos puderam fazer uma leitura crítica da sociedade, sendo capazes de enxergar um potencial para compreender a sociedade em que estão inseridos, bem como de influenciar nela a partir das suas atribuições técnicas e profissionais.

\section{REFERÊNCIAS}

BRASIL. Ministério da Educação. Lei no 9.394 de 20 de dezembro de 1996. Estabelece as Diretrizes e Bases da Educação Nacional. Disponível em: $<$ http://portal.mec.gov.br/seesp/arquivos/p df/lei9394_ldbn1.pdf $>$. Acesso em: 30 mai. 2019.

BRASIL. Ministério da Educação. Resolução $n^{\circ}$ 2, de 24 de abril de 2019. Institui as Diretrizes Curriculares Nacionais do Curso de Graduação em Engenharia. Disponível em:

$<$ http://portal.mec.gov.br/docman/agosto2018-pdf/93861-texto-referencia-dcn-deengenharia/file>. Acesso em: 20 mai. 2019.

\section{CASE CONSTRUCTION (Brasil). Escavadeira Hidráulica CX220. Disponível em:}

https://d3u1quraki94yp.cloudfront.net/cas ece/latam/assets/Brochures/Products/Prior $\%$ 20Models/folheto-escavadeira-casecx220.pdf. Acesso em: 31 jul. 2019.

DATIG, I.; RUSWICK, C. Four Quick Flips: Activities for the Information Literacy Classroom. College \& Research Libraries News, v. 74, n. 5, p. 249-251, 257, 2013.

DELORS, J. Educação: um tesouro a descobrir - Relatório para a Unesco da Comissão Internacional sobre Educação para o Século XXI. São Paulo: Editora Cortez, 2012.

FERREIRA, W. M. et al. Corantes: uma abordagem com enfoque Ciência, Tecnologia e Sociedade (CTS) usando processos oxidativos avançados. Química nova na escola, v. 40, n. 4, p 249-257, 2018.

MARIN, M. J. S. et al. Aspectos das fortalezas e fragilidades no uso das Metodologias Ativas de Aprendizagem. Revista Brasileira de Educação Médica, 34 (1), p. 13-20, 2010.

MARTINS, A. B.; MARIA, L. C. S.; AGUIAR, M. R. M. P. A. As drogas no ensino de Química. Química Nova na Escola, n. 18, p. 18-21, nov. 2003.

MASETTO, M. Docência na universidade. São Paulo: Papirus, 1998.

MORÁN, J. Mudando a Educação com Metodologias Ativas. In: SOUZA, C. A.; MORALES, O. E. T. (Orgs.). Convergências Midiáticas, Educação e Cidadania: aproximações jovens. (Volume 2). Ponta Grossa: UEPG/PROEX, 2015. Disponível em: $<$ http://www2.eca.usp.br/moran/wpconten t/uploads/2013/12/mudando_moran.pdf $>$. Acesso em: 08 mai. 2019.

PIMENTA, S. G. Docência no Ensino Superior. São Paulo: Cortez, 2008. 
ROCHA, H. M.; LEMOS, W. M. Metodologias ativas: do que estamos falando? Base conceitual e relato de pesquisa em andamento. Anais... Simpósio Pedagógico e Pesquisas em Educação. Resende: AEDB, 2014.
SAKAI, M.; HIROMI, L. G. Z. PBL: uma visão geral do método. Olho Mágico, Londrina, v. 2, n. 5/6, n. esp., 1996.

\section{DADOS BIOGRÁFICOS DOS AUTORES}

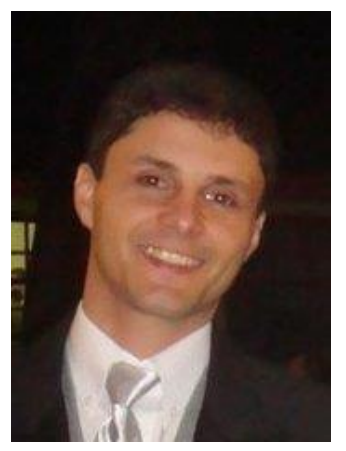

Rondinele de Oliveira Moutta possui graduação em Engenharia Química pela Pontifícia Universidade Católica do Rio de Janeiro (2005), mestrado em Biotecnologia Industrial pela Escola de Engenharia de Lorena, EEL - USP (2009) e doutorado em Bioquímica pela UFRJ (2014). Fiscal de contratos e chefe de serviços na divisão de recuperação ambiental do Instituto Estadual do Ambiente (INEA) desde 2013. Professor horista no Centro Universitário de Volta Redonda (UniFOA) desde 2014. Tem experiência na área de Engenharia Química/Bioquímica em desenvolvimento de processos, com ênfase em conversão de biomassa por via química, física ou enzimática e processos fermentativos, atuando principalmente nos seguintes temas: resíduos agroindustriais, hidrólise, fermentação, preservação e recuperação ambiental.

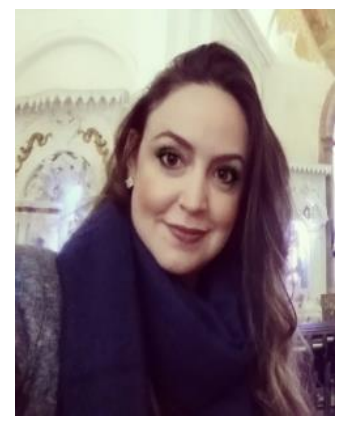

Giseli Capaci Rodrigues é Química e Farmacêutica, Mestre e Doutora em Química com ênfase em Química Orgânica, pelo Instituto Militar de Engenharia - IME. Pósdoutora em Microbiologia pelo Instituto de Microbiologia Paulo de Góes - UFRJ. Desenvolveu projeto de pesquisa junto à Indústria Farmacêutica voltado ao planejamento e à síntese de substâncias com potencial de ação terapêutica contra doenças de origem infecciosa. Atuou por nove anos em Indústria Química. Atualmente é Professora Adjunta Doutora da Universidade do Grande Rio UNIGRANRIO, onde é Bolsista 1A do Programa Institucional de Bolsas de Produtividade em Pesquisa - PROPESQ/FUNADESP - com dedicação exclusiva, desempenhando as seguintes funções: Professora da Graduação; Membro dos Núcleos Docentes Estruturantes (NDE) dos cursos de Química e Farmácia; Coordenadora de área de Subprojetos do Programa de Bolsa de Iniciação à Docência (PIBID-UNIGRANRIO/CAPES); Coordenadora Adjunta do curso de Mestrado Profissional em Ensino das Ciências (PPGEC); Orientadora de alunos de Mestrado, Iniciação Científica e Trabalho de Conclusão de Curso com projetos voltados às investigações de compostos com potencial bioatividade frente a doenças infecciosas/negligenciadas, bem como pesquisas relacionadas ao Ensino de Química e de Ciências. 